\title{
Properties of Kerosene-Aluminium Nanofluid used to Estimate the Overall Heat Transfer Rates during Regenerative/Film Cooling of Thrust Chambers
}

\author{
Abhinav Kumar, Umar Mushtaq, Muskan Raikwar, Anil Chamoli, Shahid Khan
}

\begin{abstract}
Large heat transfer rates are always desired for rocket propulsion applications as high heat loads are associated at the nozzle exit. Different strategies have been employed in order to have high heat transfer coefficients including use of liquid nitrogen, spray cooling etc. ISRO has planned to use aluminium based nano-particles with kerosene in order to cool launching vehicles including GSLV Mk III as it is the heaviest rocket that can carry large payloads. Recently, ISRO has announced to install its own International Space Station (ISS) in future and in such applications larger payloads are to be carried by the rocket. In this work, an analytical study on the thermodynamic properties of the aluminium nano-particles based kerosene nanofluid has been done and an attempt has also been made to develop a temperature and pressure dependent correlation that can be used in computational analysis of thrust chambers while film/regenerative cooling.
\end{abstract}

Keywords: Film cooling, kerosene, dodecane, thrust chambers, GSLV Mk III.

\section{INTRODUCTION}

$S_{\text {pace missions are always challenging as minor errors }}$ can result into failure of the whole system. After the first flight of Indian Space Research Organisation (ISRO) during 1979, the national agency has evolved itself on larger scales and has successfully launched Mangalyaan in 2013 and 104 nanosatellites in single PSLV-C37 flight during 2017. The space agency is now ready to launch Chandrayan-II in July, 2019 where semi-cryogenic engine GSLV Mk III (kerosene as fuel and liquid oxygen as oxidiser) is to be used to carry the heavy payloads. Recently, ISRO has announced to install its own International Space Station (ISS) in future. Installation of such heavy structures into the space is a tedious task and GSLV Mk III is the only launching vehicle is available with

Revised Manuscript Received on December 03, 2019

* Correspondence Author

Abhinav Kumar*, School of Mechanical Engineering, Lovely Professional University, Phagwara, India. Email: drabhinav@ieee.org

Umar Mushtaq, Department of Aerospace Engineering, Lovely Professional University, Phagwara, India. Email: mumarmir@gmail.com

Muskan Raikwar, Department of Aerospace Engineering, Lovely Professional University, Phagwara, India. Email: muskanraikwar1998@gmail.com

Anil Chamoli, Department of Aerospace Engineering, Lovely anilchamoli777@gmail.com

Shahid Khan, Department of Aerospace Engineering, Lovely Professional University, Phagwara, India. Email: khan.shahid1171@gmail.com Professional University, Phagwara, India. Email

ISRO to carry such large structures. Installation of ISS into orbit needs number of rocket launching programmes as it is not possible to commence whole ISS unit in a single launch due to the involvement of heavy payloads. Massive cost is involved in such missions and it is always desired to carry bulky payloads and light supporting structure (including fuel and physical structure) in a single rocket launch which can reduce the total cost of such programmes. However, it is not possible in present scenario due to the unavailability of robust materials that can handle large temperature gradients arises due to combustion of fuel and high drag. To conquer such challenges generally rocket components, like exhaust nozzles, $1^{\text {st }}$ and $2^{\text {nd }}$ stage thrust chambers and heat shields, are made with large thicknesses that can handle thermal stresses with comfort which further increase the overall weight of the system.

The immediate solution for such challenges is to use coolants that can be used to reduce the heat loads on the components through regenerative or film cooling [1]-[7]. Studies have been found where kerosene, liquid methane etc. are used for regenerative/film cooling of thrust chambers [3][8][9]. Large mass flow rates are required to match the required heat transfer rates which lead to increase the contact area of cooling channels and this further leads to increase the overall weight of the system. To get rid of this, ISRO has decided to use nano-particles especially aluminium based nano-particles [8] into the coolant (bled kerosene for initial preheat prior combustion) in order to have large heat transfer rates. In this work, aluminium based nano-particles have been proposed for the cooling of the rocket components. The base fluid is kerosene which is generally used in the $2^{\text {nd }}$ stage rockets as a liquid propellant. Also, the chemical surrogate of kerosene fuel is assumed to be dodecane $(\mathrm{C} 12 \mathrm{H} 26)$ in the present study as kerosene is refined form of it and it has an ability to replicate the chemical kinetics of the kerosene. Therefore, in the present study a comparison between the thermodynamic properties of kerosene (dodecane) and kerosene-aluminium nanofluid has been made. Generally, two properties thermal conductivity and specific heat are taking into account while considering the heat transfer aspects during the flow of fluid through the cooling channels. Therefore, in the present work, specific heat and thermal conductivity of the dodecane and dodecane-aluminium nanofluid has been examined. 
In order to use the same property data in future during simulations, an attempt has been made to fitting the data with a curve-fit as a function of temperature and pressure. The correlation has been fitted for a pressure and temperature ranges from 1 bar to 10 bar and $275 \mathrm{~K}$ to $475 \mathrm{~K}$ respectively for both dodecane and dodecane-aluminium nanofluid.

\section{PROPERTIES OF DO-DECANE AND NANOFLUID}

Thermodynamic properties specific heat and thermal conductivity) of dodecane have been extracted from NIST database. The properties of aluminium nanoparticles have been taken from commercial suppliers i.e. the specific heat of nano-particle is $837.4 \mathrm{~J} / \mathrm{kg}-\mathrm{K}$ and thermal conductivity is 30.3 $\mathrm{W} / \mathrm{mK}$. To evaluate the effective specific heat and thermal conductivity of nanofluid following correlations have been employed:

For specific heat [10]:

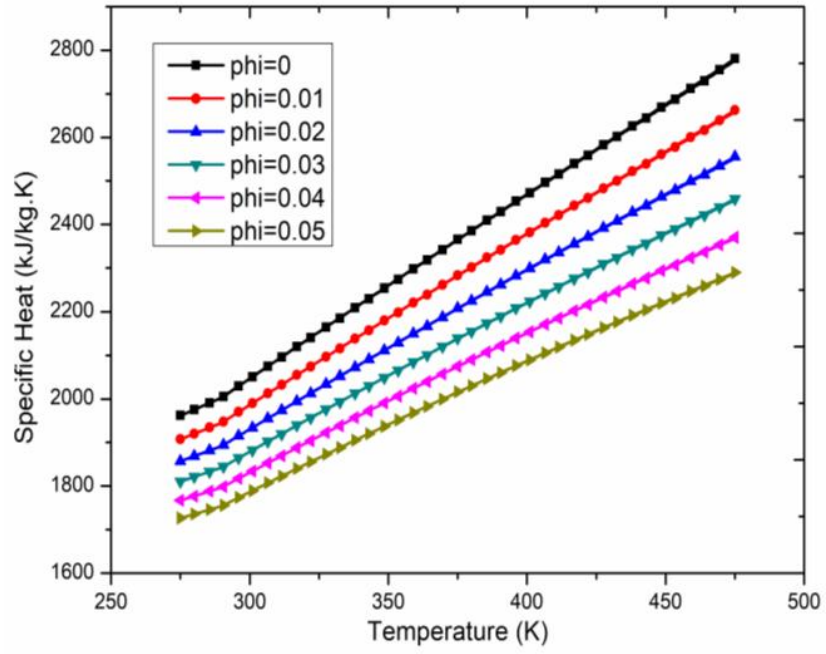

Fig. 1. Specific Heat of $n$-dodecane and its nanofluid
For thermal conductivity:

Maxwell correlation [11]

$\frac{k_{e f f}}{k_{f}}=\frac{k_{n p}+2 k_{b f}+2 \phi\left(k_{n p}-k_{b f}\right)}{k_{n p}+2 k_{b f}-\phi\left(k_{n p}-k_{b f}\right)}$

$\phi$ (phi) is a volume fraction, $\rho_{b f}$ is density of base fluid i.e. dodecane and $\rho_{n p}$ is the density of nanoparticles. In literature, researchers have worked on nanofluids where they have considered thermal conductivity correlations and achieved significant increase in the rate of heat transfers [12][13]. Specific heat of nanofluid is found to decline with the addition of nanoparticles however increased with rise in temperature [14][15].

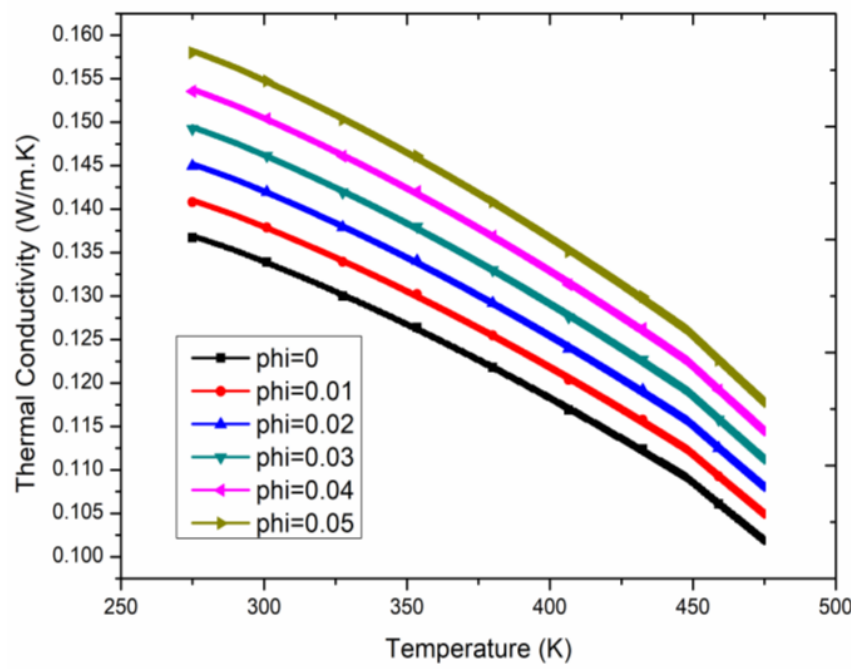

Fig. 2. Thermal conductivity of n-dodecane and its nanofluid

$c_{p, n f}=\frac{(1-\phi) \rho_{b f} c_{p, b f}+\phi \rho_{n p} c_{p, n p}}{(1-\phi) \rho_{b f}+\phi \rho_{n p}}$

(1)

Table- I: Correlation coefficients of Effective Specific Heat of nanofluid

\begin{tabular}{|l|l|l|l|l|l|}
\hline \multirow{2}{*}{$\begin{array}{l}\text { Correlation } \\
\text { Coefficients }\end{array}$} & \multicolumn{5}{|l}{ Pressures 1 bar to 10 bar and Temperature 275 K to 475 K } \\
\cline { 2 - 6 } & phi=0.01 & phi=0.02 & phi=0.03 & phi=0.04 & phi=0.05 \\
\hline $\mathbf{R}^{2}$ & 0.9998 & 0.9998 & 0.9998 & 0.9998 & 0.9998 \\
\hline $\mathrm{p}_{0}$ & 1048.395 & 1041.864 & 1032.991 & 1026.978 & 1019.252 \\
\hline $\mathrm{a}_{1}$ & -0.78949 & -0.87222 & -0.70369 & -0.77079 & 0.2018 \\
\hline $\mathrm{a}_{2}$ & 2.20129 & 1.91722 & 2.09978 & 1.86945 & 3.27692 \\
\hline $\mathrm{a}_{3}$ & -0.06646 & -0.06446 & -0.09367 & -0.09537 & -0.20495 \\
\hline $\mathrm{a}_{4}$ & $-9.47 \mathrm{E}-04$ & -0.00105 & -0.00109 & -0.00112 & -0.00117 \\
\hline $\mathrm{b}_{1}$ & -0.00293 & -0.00294 & -0.00273 & -0.00274 & -0.00175 \\
\hline $\mathrm{b}_{2}$ & $3.77 \mathrm{E}-06$ & $3.74 \mathrm{E}-06$ & $3.32 \mathrm{E}-06$ & $3.28 \mathrm{E}-06$ & $1.45 \mathrm{E}-06$ \\
\hline $\mathrm{b}_{3}$ & $-1.90 \mathrm{E}-09$ & $-1.86 \mathrm{E}-09$ & $-1.54 \mathrm{E}-09$ & $-1.50 \mathrm{E}-09$ & $-7.20 \mathrm{E}-11$ \\
\hline $\mathrm{b}_{4}$ & 0.00128 & 0.00115 & 0.00127 & 0.00116 & 0.00201 \\
\hline $\mathrm{b}_{5}$ & $-3.74 \mathrm{E}-05$ & $-3.71 \mathrm{E}-05$ & $-5.20 \mathrm{E}-05$ & $-5.38 \mathrm{E}-05$ & $-1.13 \mathrm{E}-04$ \\
\hline
\end{tabular}


The effective specific heat and thermal conductivity of the dodecane nanofluid can be calculated from (1) and (2) respectively. Fig. 1 and Fig. 2 show the effect of concentration of aluminium nano-particles on the effective specific heat and thermal conductivity of the nanofluid.

An attempt has been made to fit the variation of the nanofluid properties with pressure (1 to 10bar) and temperature (275 to $475 \mathrm{~K}$ ) for future use while performing computational studies on thrust chambers using regenerative or film cooling. (3) show the curve fit expression in which ' $T$ ' and ' $P$ ' are the variables and other are constants. Table I and Table II show the correlation coefficients for effective specific heat and thermal conductivity respectively.

$\left(\rho, \mu, c_{p}, k\right)=\frac{p_{0}+a_{1} T+b_{1} P+b_{2} P^{2}+b_{3} P^{3}}{1+a_{2} T+a_{3} T^{2}+a_{4} T^{3}+b_{4} P+b_{5} P^{2}}$
$R^{2}=1-\frac{\sum_{i=1}^{N}\left(f_{i}^{c a l}-f_{i}^{n i s t}\right)^{2}}{\left(f_{i}^{c a l}-f_{i}^{\text {mean }}\right)^{2}}$

where $f_{i}^{\text {mean }}=\frac{1}{N} \sum_{i=1}^{n} f_{i}^{c a l}$

$\mathrm{R}^{2}$ Value (4) is a statistically measured number which generally evaluated accuracy of the fit and have values between 0 (poor fit) and 1 (good fit). Table I and Table II show the value which is very close to 1 which implies developed fit is accurate and can be used in further studies.

Table- II: Correlation coefficients of Effective Thermal Conductivity nanofluid

\begin{tabular}{|l|l|l|l|l|l|}
\hline \multirow{2}{*}{$\begin{array}{l}\text { Correlation } \\
\text { Coefficients }\end{array}$} & \multicolumn{5}{|l}{ Pressures $\mathbf{1}$ bar to 10 bar and Temperature 275 K to 475 K } \\
\cline { 2 - 6 } & $\mathbf{p h i = 0 . 0 1}$ & $\mathbf{p h i}=\mathbf{0 . 0 2}$ & $\mathbf{p h i}=\mathbf{0 . 0 3}$ & $\mathbf{p h i}=\mathbf{0 . 0 4}$ & \multirow{2}{*}{ phi=0.05 } \\
\hline $\mathbf{R}^{\mathbf{2}}$ & 0.9999 & 0.9999 & 0.9999 & 0.9999 & 0.9999 \\
\hline $\mathrm{p}_{0}$ & 0.14249 & 0.1466 & 0.15211 & 0.15616 & 0.16067 \\
\hline $\mathrm{a}_{1}$ & $-2.78 \mathrm{E}-04$ & $-2.86 \mathrm{E}-04$ & $-2.95 \mathrm{E}-04$ & $-3.04 \mathrm{E}-04$ & $-3.12 \mathrm{E}-04$ \\
\hline $\mathrm{a}_{2}$ & $-2.54 \mathrm{E}-04$ & $-2.63 \mathrm{E}-04$ & $-2.50 \mathrm{E}-04$ & $-2.64 \mathrm{E}-04$ & $-2.71 \mathrm{E}-04$ \\
\hline $\mathrm{a}_{3}$ & $-6.19 \mathrm{E}-06$ & $-6.75 \mathrm{E}-06$ & $-2.81 \mathrm{E}-06$ & $-4.12 \mathrm{E}-06$ & $-4.22 \mathrm{E}-06$ \\
\hline $\mathrm{a}_{4}$ & $-7.17 \mathrm{E}-07$ & $-7.34 \mathrm{E}-07$ & $-8.00 \mathrm{E}-07$ & $-8.09 \mathrm{E}-07$ & $-8.32 \mathrm{E}-07$ \\
\hline $\mathrm{b}_{1}$ & -0.0027 & -0.00271 & -0.00265 & -0.00267 & -0.00267 \\
\hline $\mathrm{b}_{2}$ & $4.33 \mathrm{E}-06$ & $4.34 \mathrm{E}-06$ & $4.18 \mathrm{E}-06$ & $4.23 \mathrm{E}-06$ & $4.22 \mathrm{E}-06$ \\
\hline $\mathrm{b}_{3}$ & $-5.53 \mathrm{E}-09$ & $-5.54 \mathrm{E}-09$ & $-5.37 \mathrm{E}-09$ & $-5.42 \mathrm{E}-09$ & $-5.42 \mathrm{E}-09$ \\
\hline $\mathrm{b}_{4}$ & -0.00352 & -0.00353 & -0.00341 & -0.00345 & -0.00345 \\
\hline $\mathrm{b}_{5}$ & $-2.65 \mathrm{E}-05$ & $-2.94 \mathrm{E}-05$ & $2.63 \mathrm{E}-06$ & $-6.58 \mathrm{E}-06$ & $-6.48 \mathrm{E}-06$ \\
\hline
\end{tabular}

Table- III: Standard Errors involved in calculation of coefficients

\begin{tabular}{|l|l|l|l|l|l|}
\hline \multirow{2}{*}{$\begin{array}{l}\text { Correlation } \\
\text { Coefficients }\end{array}$} & \multicolumn{5}{|l}{ Standard Errors (Effective Specific Heat) } \\
\cline { 2 - 6 } & $\mathbf{p h i}=\mathbf{0 . 0 1}$ & $\mathbf{p h i}=\mathbf{0 . 0 2}$ & $\mathbf{p h i}=\mathbf{0 . 0 3}$ & $\mathbf{p h i}=\mathbf{0 . 0 4}$ & phi=0.05 \\
\hline $\mathrm{p}_{0}$ & 7.79747 & 7.34365 & 8.67307 & 8.21647 & 15.65176 \\
\hline $\mathrm{a}_{1}$ & 0.27992 & 0.29772 & 0.44131 & 0.49334 & 1.9319 \\
\hline $\mathrm{a}_{2}$ & 1.73497 & 1.73082 & 1.99474 & 2.01076 & 4.04894 \\
\hline $\mathrm{a}_{3}$ & 1.69467 & 1.67166 & 1.86916 & 1.85238 & 2.83176 \\
\hline $\mathrm{a}_{4}$ & 0.54809 & 0.52356 & 0.57297 & 0.5507 & 0.83771 \\
\hline $\mathrm{b}_{1}$ & $2.10 \mathrm{E}-04$ & $2.32 \mathrm{E}-04$ & $3.62 \mathrm{E}-04$ & $4.18 \mathrm{E}-04$ & 0.00176 \\
\hline $\mathrm{b}_{2}$ & $3.40 \mathrm{E}-07$ & $3.77 \mathrm{E}-07$ & $5.97 \mathrm{E}-07$ & $6.91 \mathrm{E}-07$ & $3.05 \mathrm{E}-06$ \\
\hline $\mathrm{b}_{3}$ & $2.38 \mathrm{E}-10$ & $2.71 \mathrm{E}-10$ & $4.38 \mathrm{E}-10$ & $5.17 \mathrm{E}-10$ & $2.34 \mathrm{E}-09$ \\
\hline $\mathrm{b}_{4}$ & $7.28 \mathrm{E}-04$ & $7.54 \mathrm{E}-04$ & $9.12 \mathrm{E}-04$ & $9.53 \mathrm{E}-04$ & 0.00216 \\
\hline $\mathrm{b}_{5}$ & $6.07 \mathrm{E}-04$ & $6.27 \mathrm{E}-04$ & $7.33 \mathrm{E}-04$ & $7.58 \mathrm{E}-04$ & 0.00121 \\
\hline
\end{tabular}


Properties of Kerosene-Aluminium Nanofluid used to Estimate the Overall Heat Transfer Rates during Regenerative/Film Cooling of Thrust Chambers

Table- IV: Standard Errors involved in calculation of coefficients

\begin{tabular}{|l|l|l|l|l|l|}
\hline \multirow{2}{*}{$\begin{array}{l}\text { Correlation } \\
\text { Coefficients }\end{array}$} & \multicolumn{5}{|l}{ Standard Errors (Effective Thermal Conductivity) } \\
\cline { 2 - 6 } & $\mathbf{p h i}=\mathbf{0 . 0 1}$ & $\mathbf{p h i}=\mathbf{0 . 0 2}$ & $\mathbf{p h i}=\mathbf{0 . 0 3}$ & $\mathbf{p h i}=\mathbf{0 . 0 4}$ & $\mathbf{p h i}=\mathbf{0 . 0 5}$ \\
\hline $\mathrm{p}_{0}$ & $1.53 \mathrm{E}-04$ & $1.57 \mathrm{E}-04$ & $1.74 \mathrm{E}-04$ & $1.75 \mathrm{E}-04$ & $1.80 \mathrm{E}-04$ \\
\hline $\mathrm{a}_{1}$ & $1.97 \mathrm{E}-07$ & $2.02 \mathrm{E}-07$ & $2.21 \mathrm{E}-07$ & $2.23 \mathrm{E}-07$ & $2.30 \mathrm{E}-07$ \\
\hline $\mathrm{a}_{2}$ & $3.63 \mathrm{E}-05$ & $3.71 \mathrm{E}-05$ & $4.06 \mathrm{E}-05$ & $4.10 \mathrm{E}-05$ & $4.22 \mathrm{E}-05$ \\
\hline $\mathrm{a}_{3}$ & $3.59 \mathrm{E}-05$ & $3.68 \mathrm{E}-05$ & $4.02 \mathrm{E}-05$ & $4.06 \mathrm{E}-05$ & $4.18 \mathrm{E}-05$ \\
\hline a $_{4}$ & $1.09 \mathrm{E}-05$ & $1.12 \mathrm{E}-05$ & $1.23 \mathrm{E}-05$ & $1.24 \mathrm{E}-05$ & $1.27 \mathrm{E}-05$ \\
\hline $\mathrm{b}_{1}$ & $7.07 \mathrm{E}-06$ & $7.01 \mathrm{E}-06$ & $7.65 \mathrm{E}-06$ & $7.45 \mathrm{E}-06$ & $7.45 \mathrm{E}-06$ \\
\hline $\mathrm{b}_{2}$ & $2.15 \mathrm{E}-08$ & $2.13 \mathrm{E}-08$ & $2.33 \mathrm{E}-08$ & $2.27 \mathrm{E}-08$ & $2.27 \mathrm{E}-08$ \\
\hline $\mathrm{b}_{3}$ & $2.06 \mathrm{E}-11$ & $2.05 \mathrm{E}-11$ & $2.25 \mathrm{E}-11$ & $2.19 \mathrm{E}-11$ & $2.19 \mathrm{E}-11$ \\
\hline $\mathrm{b}_{4}$ & $3.03 \mathrm{E}-04$ & $3.01 \mathrm{E}-04$ & $3.19 \mathrm{E}-04$ & $3.14 \mathrm{E}-04$ & $3.14 \mathrm{E}-04$ \\
\hline $\mathrm{b}_{5}$ & $2.68 \mathrm{E}-04$ & $2.67 \mathrm{E}-04$ & $2.83 \mathrm{E}-04$ & $2.78 \mathrm{E}-04$ & $2.78 \mathrm{E}-04$ \\
\hline
\end{tabular}

\section{CONCLUSIONS}

In the present work, an effort has been made to understand the effect of Aluminium nano-particle concentration on the thermodynamic properties of the dodecane surrogate fuel of kerosene. Correlations (1) and (2) are used to calculate the effective thermodynamic properties of the nanofluid. It has been noticed that the effective specific heat of nanofluid is decreasing with the concentration of the nano-particles (phi= $1 \%$ to $5 \%$ ) and effective thermal conductivity is found to increase with the nano-particle concentration. In order to fit this behavior, correlations have been formed for each concentration as a function of temperature (275 to $475 \mathrm{~K})$ and pressure ( 1 to 10 bar). The standard errors (Table III and Table IV) are found to be very small effective thermal conductivity calculations and are little higher for specific heats however can be considered for the computational analysis on thrust chambers or nozzle cooling applications.

\section{REFERENCES}

1. J.-G. Kim, K.-J. Lee, S. Seo, Y.-M. Han, H.-J. Kim, and H.-S. Choi, "Film cooling effects on wall heat flux of a liquid propellant combustion chamber," in 42nd AIAA/ASME/SAE/ASEE Joint Propulsion Conference \& Exhibit, 2006, p. 5196.

2. R. Arnold, D. I. Suslov, and O. J. Haidn, "Film cooling in a high-pressure subscale combustion chamber," J. Propuls. power, vol. 26 , no. 3, pp. 428-438, 2010.

3. J. Song and B. Sun, "Thermal-structural analysis of regenerativelycooled thrust chamber wall in reusable LOX / Methane rocket engines," Chinese J. Aeronaut., vol. 30, no. 3, pp. 1043-1053, 2017.

4. S. R. Shine and S. S. Nidhi, "Review on fi $1 \mathrm{~m}$ cooling of liquid rocket engines," Propuls. Power Res., vol. 7, no. 1, pp. 1-18, 2018.

5. T.-S. Wang, "Transient three-dimensional startup side load analysis of a regeneratively cooled nozzle," Shock Waves, vol. 19, no. 3, pp. 251-264, 2009

6. C. H. Marchi, F. Laroca, A. F. C. da Silva, and J. N. Hinckel, "Numerical solutions of flows in rocket engines with regenerative cooling,” Numer. Heat Transf. Part A Appl., vol. 45, no. 7, pp. 699-717, 2004.

7. A. W. Mirand, M. H. Naraghi, and I. Introduction, "Analysis of Film Cooling and Heat Transfer in Rocket Thrust Chamber and Nozzle," no. January, pp. 1-14, 2011.

8. D. K. Agarwal, A. Vaidyanathan, and S. S. Kumar, "Investigation on convective heat transfer behaviour of kerosene-Al2O3 nanofluid," Appl. Therm. Eng., vol. 84, pp. 64-73, 2015.

9. J. Song and B. Sun, "Damage localization effects of the regenerativelycooled thrust chamber wall in LOX / methane rocket engines," Chinese J. Aeronaut., vol. 31, no. 8, pp. 1667-1678, 2018.

10. J. A. Eastman, S. R. Phillpot, S. U. S. Choi, and P. Keblinski, "Thermal transport in nanofluids," Annu. Rev. Mater. Res., vol. 34, pp. 219-246, 2004.

11. W. Yu, D. M. France, J. L. Routbort, and S. U. S. Choi, "Review and comparison of nanofluid thermal conductivity and heat transfer enhancements," Heat Transf. Eng., vol. 29, no. 5, pp. 432-460, 2008.

12. L. Fedele, L. Colla, and S. Bobbo, "Viscosity and thermal conductivity measurements of water-based nanofluids containing titanium oxide nanoparticles,” Int. J. Refrig., vol. 35, no. 5, pp. 1359-1366, 2012.

13. Y. Xuan and W. Roetzel, "Conceptions for heat transfer correlation of nanofluids," Int. J. Heat Mass Transf., vol. 43, no. 19, pp. 3701-3707, 2000.

14. L. Spernarth and S. Magdassi, "Preparation of ethyl cellulose nanoparticles from nano-emulsion obtained by inversion at constant temperature," Micro Nano Lett., vol. 2, no. 4, pp. 90-95, 2007.

15. I. M. Shahrul, I. M. Mahbubul, S. S. Khaleduzzaman, R. Saidur, and M. F. M. Sabri, "A comparative review on the specific heat of nanofluids for energy perspective," Renew. Sustain. Energy Rev., vol. 38, pp. $88-98,2014$.

\section{AUTHORS PROFILE}

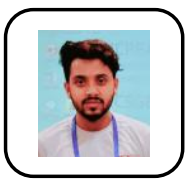

Abhinav Kumar is pursuing his Doctorate in Mechanical Engineering from Lovely Professional University, Punjab, India. He has completed his master's in thermal engineering specialization from Lovely Professional University in 2014 and bachelor's in Mechanical Engineering from Punjab Technical University in 2011. He has published many SCI and Scopus indexed articles in various journals and has attended many international conferences. His area of research is vast including superconducting magnetic energy storage systems, superconducting fault current limiters, high temperature superconducting cable design \& cooling, cryogenic fluid properties, nozzle cooling, computational fluid dynamics and solar energy storage systems. He is one of the reviewers for SCI and Scopus indexed journals and conferences. $\mathrm{He}$ has been awarded with University Academic Honor and University Honor Roll for his excellent academic records. He is holding Student IEEE and life membership of Indian Society of Heat and Mass Transfer (ISHMT).

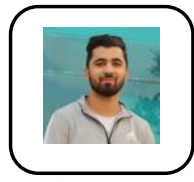

Society.
Umar Mushtaq is an undergraduate student in Aerospace Engineering from Lovely Professional University since 2017. He is an active member of Aeronautical Society of India and Royal Aeronautical 
Recently, he has presented research articles in Indiana Summit and RAFAS 2019 international conferences. His area of research is high speed aerodynamics, wind tunnel testing, cryogenics, computational fluid dynamics, high temperature heat transfer, high temperature materials, rocket fuels and electric aircraft energy management systems.

Muskan Raikwar is an undergraduate student in Aerospace Engineering from Lovely Professional University since 2017 . She is actively participated in many technical events and competitions. Recently, she has participated in-flight experimentation on 6 seater Cessna aircraft at Flight Laboratory, IIT Kanpur, India. Her area of interest is aerodynamics, high temperature materials, nozzle cooling and heat transfer.

Anil Chamoli is an undergraduate student in Aerospace Engineering from Lovely Professional University since 2017. He is the Head of Propulsion systems at Euroavia- a technical student organization of Lovely Professional University. $\mathrm{He}$ is working on different area of research including nozzle designs, high temperature materials and rocket fuels. He has participated in many national technical competitions and won prizes.

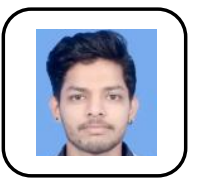

Shahid Khan is an undergraduate student in Aerospace Engineering from Lovely Professional University since 2017. He has lead a technical competitive event and won $2^{\text {nd }}$ prize in Noviet Space Problem Solution in India. In the early stages of his research career, he is working on rockets fuels and the cryogenic fuel storage in earth-storable heat exchangers. 